\title{
Cardiac Autonomic Modulation of Healthy Individuals and Patients with Chronic Obstructive Pulmonary Disease During Spontaneous and Controlled Breathing
}

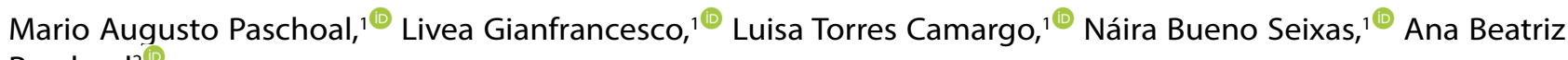
Paschoal $^{2}$

Pontifícia Universidade Católica de Campinas, 'São Paulo, SP - Brazil

Faculdade de Ciências Médicas da Santa Casa de São Paulo, ${ }^{2}$ SP - Brazil

\section{Abstract}

Background: Lung diseases and different forms of breathing may interfere with cardiac autonomic modulation (CAM).

Objective: To compare CAM in individuals with chronic obstructive pulmonary disease (COPD) with healthy individuals during spontaneous breathing (SB) and controlled breathing (CB).

Methods: Cross-sectional study involving 30 individuals selected by convenience, divided into COPD group $(n=19)$ and control group (CG; $n=12)$. All participants were submitted to heart beat recordings during five minutes at rest $(\mathrm{SB})$ and another five minutes during $\mathrm{CB}$ performed at six cycles/min. CAM was made by assessment of the heart rate variability (HRV) through time domain (TD) and frequency domain (FD). Comparisons between groups were performed by Mann Whitney test, and significance level was set at $\mathrm{p}<0.05$.

Results: During SB, HRV TD and FD indices were higher in the controls than in the COPD group, respectively - RR intervals ( $53.2 \mathrm{~ms}$ versus $36.6 \mathrm{~ms})$, RMSSD $(42.1 \mathrm{~ms}$ versus $26.6 \mathrm{~ms})(\mathrm{p}<0.05)$, total power $\left(28322.8 \mathrm{~ms}^{2} / \mathrm{Hz}\right.$ versus $\left.2011.6 \mathrm{~ms}^{2} / \mathrm{Hz}\right)$, and high-frequency band $\left(800.5 \mathrm{~ms}^{2}\right.$ versus $\left.330.7 \mathrm{~ms}^{2}\right)$. During $\mathrm{CB}$, the $\mathrm{CG}$ also showed higher values for the TD parameters pNN50 (11.7\% versus 5.1\%), RMSSD (48.3 ms versus $26.7 \mathrm{~ms})$, and SD of RRi (64.9 ms versus $44.7 \mathrm{~ms})$, as well as for the low-frequency component of FD analysis $\left(2848.6 \mathrm{~ms}^{2}\right.$ versus $\left.1197.9 \mathrm{~ms}^{2}\right)$.

Conclusion: COPD patients have different CAM when compared with healthy individuals during spontaneous (SB) and controlled breathing (CB). (Int J Cardiovasc Sci. 2020;33(1):79-86)

Keywords: Autonomic Nervous System; Heart Rate; Respiratory Rate.

\section{Introduction}

Cardiac autonomic modulation (CAM) is essential for the preservation of heart function according to metabolic needs, contributing to the maintenance of internal stable conditions. ${ }^{1,2}$ Time variation between heart beats is considered normal and is related to greater or lesser activation of sympathetic and parasympathetic systems in response to central and peripheral stimuli. ${ }^{3-5}$

Among the events that may interfere with the physiological oscillations of the heart rate (HR), the most prominent are those originating from respiration..$^{6,7}$ Therefore, any disease that may impair breathing in some way, such as chronic obstructive pulmonary disease (COPD), tend to interfere with cardiovascular mechanisms ${ }^{8-10}$ by affecting the RR intervals (RRi) of the cardiac cycle and, consequently, the CAM. ${ }^{5,8,11,12}$

Changes in the CAM can be detected and quantified by analysis of the heart rate variability (HRV). In studies on spontaneous breathing in patients with COPD, however, HRV analysis has yielded conflicting results. ${ }^{11-13}$ Part of this controversy may be due to the use of certain

Mailing Address: Mario Paschoal

Av. John Boyd Dunlop, s/n. Postal Code: 13060-904, Campus II, Campinas, São Paulo, SP - Brazil.

E-mail: mapascka@gmail.com 
drugs that cannot be withdrawn from patients during data collection, and the inclusion of patients with different disease severity and, consequently, different cardiovascular conditions.

Other methods to assess the CAM consist of standardized autonomic functional tests, including controlled breathing (CB) techniques, which promote the increase of respiratory sinus arrhythmia frequently employed as an index of cardiac parasympathetic control. During CB, the oscillatory components present in the high frequency band $(0.15$ to $0.4 \mathrm{~Hz})$ of $\mathrm{HRV}$, related to cardiac parasympathetic activity, are generally potentiated ${ }^{1,14-16}$ and sensitive changes in the RRi are documented.

Considering these assumptions, the objective of the present study was to evaluate and compare the CAM in COPD patients with CAM in healthy people, subjected to spontaneous breathing (SB) and CB trials, to identify the presence of cardiac dysautonomia in COPD and how much the CB may interfere with cardiac modulation of these patients.

\section{Method}

Cross-sectional observational study approved by the Ethics Committee in Research Involving Human Beings of the Pontifical Catholic University of Campinas (PUC Campinas - approval number 393.938), São Paulo state, Brazil.

\section{Selection of Volunteers}

From a total of 40 COPD patients preselected from the outpatient physiotherapy clinic, 18 met the inclusion criteria. The sample calculation (20\% error margin and $90 \%$ confidence level) indicated a minimum of 13 COPD patients. All of them were clinically stable and had mild or moderate COPD, with clinical diagnosis confirmed by specialists. Also, they were ex-smokers (who had quit smoking at least 6 months before intervention), non-alcoholic, did not participate in any physical activity program, and had a body mass index (BMI) between 20 and $35 \mathrm{~kg} / \mathrm{m}^{2}$.

In addition, a further 12 healthy individuals (control group - CG) were selected, who met the following inclusion criteria: age group similar to that of the COPD, BMI between 20 and $35 \mathrm{~kg} / \mathrm{m}^{2}$, had not performed any regular physical activity in the last six months and did not use any medication.
The study was conducted at the outpatient physiotherapy clinic of PUC Campinas and all participants signed the consent form developed in accordance with Resolution 466/12 of the National Health Council.

\section{Anthropometric and Clinical Assessment}

The clinical assessment consisted of clinical history, measurement of heart rate (HR) and blood pressure (BP), cardiac and pulmonary auscultation, and measurement of peripheral oxygen saturation $\left(\mathrm{SpO}_{2}\right)$ by a pulse oximeter (Nonin ${ }^{\circledR}$, USA). Anthropometric evaluation consisted of the measurement of weight and height using the Filizola ${ }^{\circledR}$ scale (São Paulo, Brazil), for BMI calculation.

\section{Heart Rate Measurement in SB and CB}

Before heart rate measurement in SB or CB conditions, we confirmed that each volunteer had followed the protocol instructions to refrain from tea, soda, coffee or chocolate on the day of registration and that they had had a good night's sleep before the test.

Heart rate recording was performed using a Polar RS800C ${ }^{\circledR}$ heart rate monitor (Kempele, Finland), in a room at $23^{\circ} \mathrm{C}$ of temperature. The volunteers were instructed to relax, and not to move or talk during the recordings.

First, participants were asked to stand on a bench, where they remained for $5 \mathrm{~min}$ before the beginning of the recordings. During the first five minutes of heartbeat recording, the volunteers were asked to breath spontaneously, followed by another five minutes of $\mathrm{CB}$.

CB was performed by 5 seconds (s) for inspiration and $5 \mathrm{~s}$ for expiration, at six respiratory cycles per minute, as proposed by Andresen et al., ${ }^{17}$ Instructions on breathing were given orally by the investigator who performed the test and used a timer to control the process. Participants were asked to perform diaphragmatic breathing, i.e., by contracting the diaphragm.

Subsequently, the $\mathrm{RRi}$ recordings were sent to a computer via an interface (Polar $\mathrm{IR}^{\circledR}$ interface - Kempele, Finland), and HRV was analyzed using the Polar Precision Performance ${ }^{\circledR}$ software (Kempele, Finland).

\section{Data Analysis}

Since HRV analysis was based on RRi recordings obtained under controlled conditions, there was a great concern about possible artifacts, and thus a very narrow filter (of the own software) was applied. 
Therefore, it was possible to obtain HR recordings under stationary conditions, which visually confirmed by the HR tachogram analysis. The data obtained during $\mathrm{SB}$ and $\mathrm{CB}$ was analyzed in the time domain (TD) and frequency domain (FD) of HRV.

In the TD the following parameters were assessment, according to the European Society of Cardiology and the North American Society of Pacing and Electrophysiology Task Force. ${ }^{18}$

a) mean RRi; b) standard deviation of the mean RRi (SD RRi) - that depends on cardiac sympathetic and parasympathetic tones; c) square root of the mean of the sum of the squares of differences between adjacent normal to normal (NN) intervals (RMSSD), which expresses cardiac parasympathetic tone; d) mean HR (bpm); e) number of pairs of adjacent $\mathrm{NN}$ intervals differing by more than $50 \mathrm{~ms}$ in the entire recording divided by the total number of all NN intervals (pNN50), which expresses cardiac parasympathetic tone. The results of RRi, SD RRi and RMSSD were expressed in milliseconds (ms), while pNN50 values were expressed as percentage.

In the FD, the following indexes were calculated based on the fast Fourier transform (FFT) algorithm:

a) Total power (TP) - obtained in the range of 0.0 to $0.4 \mathrm{~Hz}$; it is composed of the sum of the following indices: ultra-low frequency (ULF 0.0 to $0.003 \mathrm{~Hz}$ ), very low frequency (VLF -0.003 to $0.04 \mathrm{~Hz}$ ), low frequency (LF 0.04 to $0.15 \mathrm{~Hz}$ ) and high frequency (HF -0.15 to $0.4 \mathrm{~Hz}$ ) power. ${ }^{18}$ The TP expresses the total variability resulting from the fundamental oscillatory components present during recording; $b$ ) density of oscillatory components present in the LF band reflecting both sympathetic and cardiac parasympathetic activities; ${ }^{1,19}$ c) density of oscillatory components present in the HF band, reflecting the cardiac parasympathetic activity. ${ }^{1,19}$

LF and HF were also calculated in normalized units (n.u.) as proposed by Pagani et al., ${ }^{20}$ and the European Society of Cardiology and the North American Society of Pacing and Electrophysiology Task Force, ${ }^{18}$ and expressed as the percentage of contribution of each branch of the ANS to the autonomic modulation of the heart. Finally, the LF/HF ratio was also calculated.

\section{Statistical Analysis}

Values of the TD and FD indexes of the HRV were inserted in tables and analyzed by the GraphPad Prism $4.0^{\circledast}$ statistical program (San Diego, California, USA).
The Shapiro-Wilk test was used to test normality of data distribution and showed a non-normal distribution of HRV values, which were then compared by the MannWhitney test was then used to compare these the clinical and anthropometric data. Also, this same test was applied to compare the HRV parameters obtained during SB and $\mathrm{CB}$ within group and between the groups. Due to their normal distribution, anthropometric and clinical data were compared by the paired Student's $t$ test to analyze the differences between the means. The level of significance was set at $\mathrm{p}<0.05$.

\section{Results}

There was no significant difference in anthropometric data between the CG and the COPD group (Table 1). The COPD group showed significantly higher $\mathrm{BP}$ values and lower $\mathrm{SpO}_{2}$ compared with controls.

During SB, in the TD parameters, statistical differences were found in SD RRi and RMSSD index, which were reduced in individuals with COPD (Table 2). In the FD, TP and HF were statistically lower in the COPD group, confirming the reduction of both parasympathetic and sympathetic cardiac tones in COPD.

During $\mathrm{CB}$, the COPD group showed significantly lower values of SD RRi, RMSSD and pNN50 (Table 3). For the HRV indexes in FD, significant differences were found in PT, LF $\left(\mathrm{ms}^{2}\right)$ and $\mathrm{HF}\left(\mathrm{ms}^{2}\right)$, which were reduced in the COPD group.

Figure 1 depicts the values of median TP during SB and $C B$, showing a great difference $(p<0.0001)$ between the groups, with higher values for the CG.

Table 4 shows the medications used by the patients during data collection. It is noteworthy that, at the request of the ethics committee, the researchers did not interfere with patients' usual medications during data collection.

\section{Discussion}

The main finding of the present study was that COPD patients showed changes in CAM, characterized by lower sympathetic and parasympathetic modulation during $\mathrm{SB}$ and $\mathrm{CB}$. In addition to this, other relevant results are discussed below.

First, it is worth pointing out that all factors that could be sources of bias in the analyses were controlled during patients' selection and before and during data collection. These factors included age, body weight, functional 
Table 1 - Clinical and anthropometric characteristics of the study groups

\begin{tabular}{lccc} 
& COPD $(\mathbf{n}=\mathbf{1 8})$ & Control group (n= 12) & p-values \\
\hline Age (years) & $62.1 \pm 8.7$ & $47.9 \pm 19.0$ & 0.34 \\
Weight (kg) & $69.4 \pm 16.5$ & $63.7 \pm 10.3$ & 0.89 \\
Height (cm) & $159.8 \pm 8.9$ & $159.9 \pm 8.0$ & 0.98 \\
BMI (kg/m $)$ & $26.9 \pm 5.4$ & $25.1 \pm 4.0$ & 0.77 \\
Rest systolic BP (mmHg) & $125.5 \pm 17.8$ & $69.1 \pm 7.9$ & $\mathrm{p}=0.007^{*}$ \\
Rest diastolic BP (mmHg) & $78,8 \pm 10.2$ & $73.9 \pm 12.1$ & $\mathrm{p}=0.01^{*}$ \\
Rest HR (bpm) & $72.6 \pm 12.2$ & $15.5 \pm 2,8$ & 0.87 \\
Rest resp. freq. (rpm) & $18.0 \pm 2.8$ & $97.1 \pm 1.8$ & 0.34 \\
SpO & $95.3 \pm 1.5$ & & $\mathrm{p}=0.006^{*}$ \\
\hline
\end{tabular}

COPD: chronic obstructive pulmonary disease; BMI: body mass index; HR: heart rate; bpm: beats per minute; rpm: respiration per minute; BP: blood pressure; $\mathrm{SpO}_{2}$ : peripheral oxygen saturation; * $p \leq 0.05$ paired Student's $t$ test; data in mean \pm standard deviation.

Table 2 - Parameters of time and frequency domains of the heart rate variability during spontaneous breathing (SB)

\begin{tabular}{|c|c|c|c|c|}
\hline & & $\operatorname{COPD}(n=18)$ & CG $(n=12)$ & p-values \\
\hline \multirow{4}{*}{$\mathrm{TD}$} & RRi (ms) & 889.0 & 902.5 & 0.32 \\
\hline & Sd RRi (ms) & 36.6 & 53.2 & $0.04^{*}$ \\
\hline & RMSSD (ms) & 26.6 & 42.1 & $0.03^{*}$ \\
\hline & pNN50 (\%) & 5.4 & 8.5 & 0.47 \\
\hline \multirow{6}{*}{ FD } & $\mathrm{TP}\left(\mathrm{ms}^{2} / \mathrm{Hz}\right)$ & $2,011.6$ & $28,322.8$ & $\mathrm{p}<0.0001^{*}$ \\
\hline & $\mathrm{LF}\left(\mathrm{ms}^{2}\right)$ & 472.8 & $1,186.3$ & 0.81 \\
\hline & LF (un) & 63.9 & 53.4 & 0.54 \\
\hline & $\mathrm{HF}\left(\mathrm{ms}^{2}\right)$ & 330.7 & 800.5 & $\mathrm{p}=0.04^{*}$ \\
\hline & HF (un) & 36.0 & 46.2 & 0.54 \\
\hline & $\mathrm{LF} / \mathrm{HF}$ & 2.25 & 2.1 & 0.62 \\
\hline
\end{tabular}

capacity acquired through physical training, caffeine intake, sleep hours, room temperature and circadian rhythm of HR. ${ }^{19,21}$

In addition, medications used by the patients may have influenced the results. However, one of the objectives of this investigation was to know how patients with COPD would react when they were submitted to SB and CB trials at the same conditions of their daily lives, which included their usual medications. Also, despite our concern about the influence of medications on HRV measurements, it is worth mentioning that there are studies that have concluded that anticholinergic or $\beta$-agonist drugs do not interfere with these measures.

The only variable related to anthropometric data that may draw attention would be age, particularly due to the high standard deviation in the CG. However, no significant difference between the groups was found according to the p-value (Table 1). 
Table 3 - Parameters of time and frequency domains of the heart rate variability during controlled breathing (CB)

\begin{tabular}{|c|c|c|c|c|}
\hline & & $\operatorname{COPD}(n=18)$ & CG $(n=12)$ & p-value \\
\hline \multirow{4}{*}{ TD } & RRi (ms) & 912.2 & 907.6 & 0.72 \\
\hline & SD iRR (ms) & 44.7 & 64.9 & $0.02^{*}$ \\
\hline & RMSSD (ms) & 26.7 & 48.3 & $0.004^{*}$ \\
\hline & pNN50 (\%) & 5.1 & 11.7 & $0.01^{*}$ \\
\hline \multirow{6}{*}{ FD } & $\mathrm{TP}\left(\mathrm{ms}^{2} / \mathrm{Hz}\right)$ & $2,555.3$ & $18,447.1$ & $\mathrm{p}<0.0001^{*}$ \\
\hline & $\mathrm{LF}\left(\mathrm{ms}^{2}\right)$ & $1,197.9$ & $2,848.6$ & $0.05^{*}$ \\
\hline & LF (un) & 84.1 & 71.9 & 0.31 \\
\hline & $\mathrm{HF}\left(\mathrm{ms}^{2}\right)$ & 232.8 & 780.0 & $0.004^{*}$ \\
\hline & HF (un) & 15.8 & 28.0 & 0.31 \\
\hline & $\mathrm{LF} / \mathrm{HF}$ & 7.4 & 5.9 & 0.27 \\
\hline
\end{tabular}

CG: control group; COPD: chronic obstructive pulmonary disease; TD: time domain; DF: frequency domain; SD: standard deviation; RRi: RR intervals; RMSSD: root mean square standard deviation of RRi; pNN50: percentage of adjacent RRi that are equal or superior to 50ms; TP: total power; LF: low frequency; HF: high frequency; ms: milliseconds; Hz: Hertz; u.n. $=$ normalized units. ${ }^{*} p \leq 0.05$, Mann-Whitney $U$ test; data expressed in median.

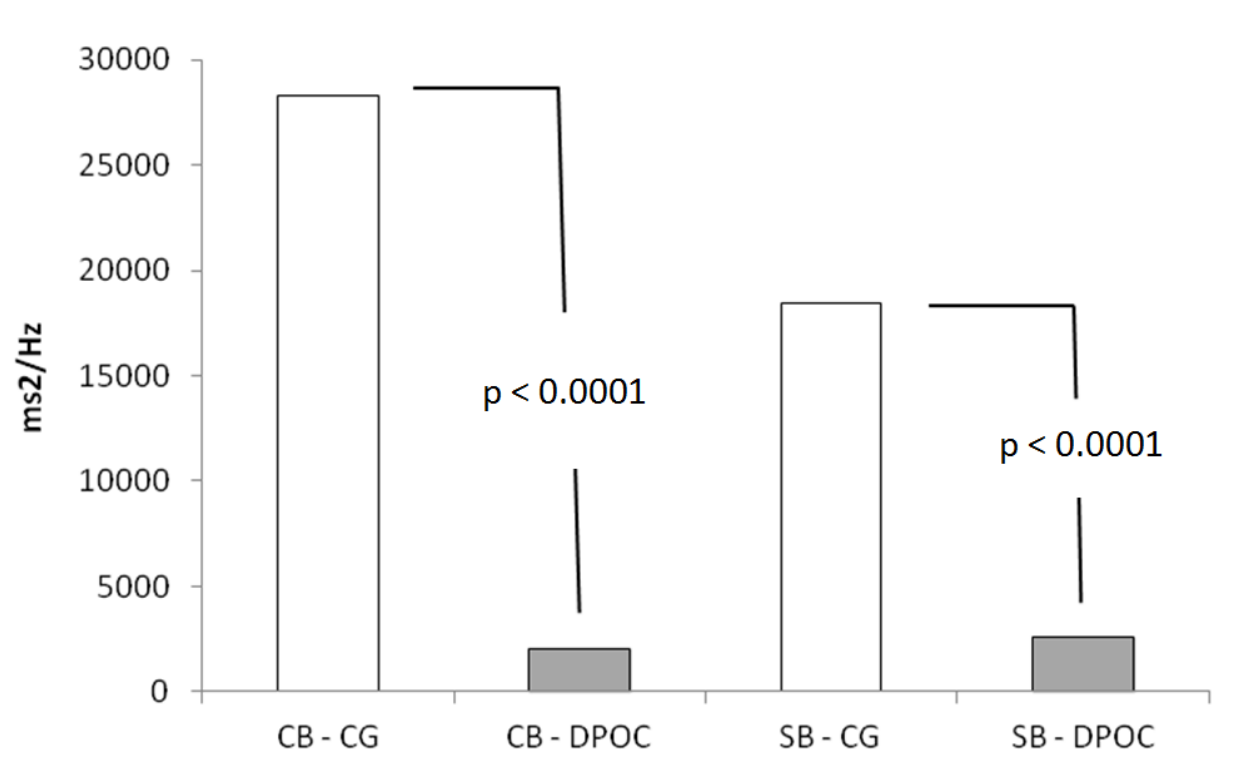

Figure 1 - Median values of total power (TP) in the Control Group (CG) and in Chronic Obstructive Pulmonary Disease (COPD) group during spontaneous breathing (SB) and controlled breathing (CB); Mann-Whitney U test.

With respect to clinical data, although COPD patients showed higher BP values than controls, these values were within normal range and probably had no effect on autonomic modulation. ${ }^{21,22}$ Similarly, despite lower in COPD than controls, $\mathrm{SpO}_{2}$ values were also within normal standards. According to Schettino et al., ${ }^{23}$ and
Dourado et al., ${ }^{24}$ significant falls in $\mathrm{SpO}_{2}$ may occur even in the resting state; however, these changes are documented only in advanced stages of the disease.

In a previous study by our group published in 2002, ${ }^{11}$ which included analysis of HRV in COPD, we already showed that patients with COPD had lower values of 


\begin{tabular}{|c|c|}
\hline $\begin{array}{l}\text { COPD } \\
\text { Group }\end{array}$ & Medications \\
\hline 1 & Losartan, Haloperidol, acetylsalicylic acid (ASA) \\
\hline 2 & Alenia \\
\hline 3 & ASA, Sinvastatin \\
\hline 4 & Formoterol \\
\hline 5 & Alenia spray \\
\hline 6 & Without medications during data collection \\
\hline 7 & Alenia, ASA, Budesonide \\
\hline 8 & $\begin{array}{l}\text { Aerogold, Sinvastatina, Losartan, AAS, Alenia, } \\
\text { Budesonide }\end{array}$ \\
\hline 9 & Aerolin spray, Salbutamol, Simvastatin \\
\hline 10 & Captopril, Alenia \\
\hline 11 & Simvastatin \\
\hline 12 & Simvastatin, Aerolin, AAS \\
\hline 13 & Simvastatin, Enalapril \\
\hline 14 & Ferrous sulfate, Alenia, azathioprine, folic acid \\
\hline 15 & Carvedilol, Furosemide, Alenia \\
\hline 16 & Alenia, Enalapril \\
\hline 17 & Enalapril, hydrochlorizide, Alenia, Aerolin \\
\hline 18 & Without medications during data collection \\
\hline
\end{tabular}

SD RRi than healthy individuals, corroborating other works. ${ }^{20,25,26} \mathrm{~A}$ reduction in SD RRi can be associated with the time a disease affects the cardiovascular system, disease severity and the use of some drugs. The SD $R R i$ is also influenced by respiratory, vasomotor and thermoregulatory stimuli, among others. ${ }^{27}$

Another result obtained by us in $2002^{11}$ and confirmed in the present study was that COPD patients had lower $\mathrm{TP}$ values during SB. In the present study, besides the fact that TP values in COPD were decreased during SB, they were also lower than CG group during CB. These results lead us to suggest that the investigation of the TP index is fundamental when the aim is to evaluate the presence of cardiac dysautonomia in COPD patients (Figure 1).

Therefore, we have one index of TD (SD RRi) and one index of FD (TP) that confirm the reduction in HRV in the COPD group. Maybe the most important problem that causes changes in the indexes of total variability is related to characteristics of the respiratory system in COPD. The less compliant thoracic-pulmonary system does not allow great changes in tidal volume, regardless of the form of breathing interfering with the venous return to the heart.

This lower complacency decreases the volume of blood directed to the right atrium during the inspiratory phase and the lower venous return tends to decrease HRV at rest, and thereby is one of the important factors involved in the reduction of the autonomic modulation of the heart of these patients.

The impaired blood flow from the right ventricle to the lungs may also contribute to these HRV changes. Patients with COPD have greater resistance to blood circulation in the heart-lung circuit, which requires more force from the heart. This may result in increased sympathetic tone and decreased vagal tone. ${ }^{11,21}$

Other aspects to be considered in HRV reduction, according to Van Gestel and Steier, ${ }^{28}$ are recurrent hypoxemia, hypercapnia, increased intrathoracic pressure due to airway obstruction, increased respiratory effort, and asystemic inflammation.

Our results suggest that the tendency of increase in sympathetic tone to overcome altered pressure in the heart-lung circuit of COPD, has interfered with the absolute and relative index values of the LF component - LF $\left(\mathrm{ms}^{2}\right)$ and LF (un) - during the SB, so that they did not differ from the values presented by the CG. Also, during SB, TP values in COPD patients were only $7.1 \%$ of those shown by the CG. However, in CB, TP increased by $27.0 \%$ in the COPD group compared to that obtained during SB and was $13.8 \%$ of that presented by the CG.

These findings reveal that in COPD, even with its limitations related to complacency of the thoracicpulmonary system, the TP is increased by almost 100\% during deeper, oriented breathing. Despite this, COPD patients still showed significantly lower values of TP $(\mathrm{p}<0.0001)$ than the CG. Therefore, we suggest that, during diaphragmatic breathing, COPD patients experience positive changes in $\mathrm{CAM},{ }^{14}$ despite significantly lower values of PT compared with controls.

Considering the analysis of HRV through TD variables, it is known that the lower the frequencies of the ventilatory cycles, as performed during the $\mathrm{CB}$ trial, the higher the values of TD indexes in HRV. ${ }^{14}$ However, the COPD group showed similar pNN50 and RMSSD values during both $\mathrm{CB}$ and $\mathrm{SB}$, differently from what 
was observed with the CG, which showed elevation of the two parameters during $\mathrm{CB}$.

Similar results were reported by Gunduz et al. ${ }^{26}$ in COPD patients during SB, with lower RMSSD (25.0 \pm $10.0 \mathrm{~ms}$ vs $60.0 \pm 35.0 \mathrm{~ms})$ and pNN50 values $(11.8 \pm 9.4$ vs $15.7 \pm 8.1 \%$ ) compared with healthy individuals. Reis et al., ${ }^{12}$ reported RMSSD values of $17.7 \pm 6.1 \mathrm{~ms}$ and $18.3 \pm$ 15.6 ms during $C B$ and $S B$, respectively in COPD patients. These values were lower than those observed in controls, and lower than those presented by our volunteers with COPD. The authors, however, did not evaluate pNN50 in these patients.

Although many clinicians believe that patients with COPD tend to have elevated cardiac sympathetic tone, the present study and other studies have shown that both the LF index (considered mainly as a sympathetic component) and the LF/HF ratio (considered mainly as a sympathetic component when greater than 1) in these patients are not different from those in healthy subjects (Tables 2 and 3). 12,28,29

In the present study, the absolute values found in the LF band $\left(\mathrm{LFms}^{2}\right)$ were lower in the COPD group than in CG. However, when these data were analyzed in standardized units (LFun), the percentage of sympathetic contribution to the autonomic modulation of the heart was not different between COPD patients and the CG. In other words, when ULF and VLF values were excluded from the analysis, the percentage of the LF band in COPD was similar to that presented by the CG.

Our results are similar to those of Antonelli Incalzi et al., ${ }^{29}$ who also reported that sympathetic modulation decreases according to the severity of COPD. They also confirm the statement by Carvalho et al. ${ }^{5}$ who reported reductions in HRV indexes that reflect not only parasympathetic modulation alone but also sympathetic and parasympathetic modulation together in COPD patients.

In relation to the absolute index of $\mathrm{HF}$, COPD patients showed lower values as compared with the CG. This is in accordance with that observed by Pantoni et al., ${ }^{9}$ who found lower values of the HF components in absolute units in these patients. This suggests that this parameter of the HRV analysis is decreased in COPD patients, and hence should be carefully observed when dealing with this group of patients.

The lower values of HF in COPD were more significant during $\mathrm{CB}$ than $\mathrm{SB}$, which agrees with the data reported by Reis et al., ${ }^{12}$ According to these authors, during $C B$, there is an increase in tidal volume and in respiratory rate in healthy individuals. Therefore, the respiratory pattern performed during the $\mathrm{CB}$ protocol could affect lung compliance and pulmonary stretch receptors, and consequently increase the values of LF, HF and TP indexes of HRV. On the other hand, in COPD patients, changes in chest expansion and pulmonary volume are less evident. The elevated and unchanged intrapulmonary pressure reduces venous return, resulting in lower RRi oscillations and changes in cardiocirculatory adjustments promoted by the autonomic nervous system.

As a study limitation, we could not determine the exact volume of air mobilized during the breaths, which would allow the establishment of the relationship between the volume of air during breathing and respective changes in HRV measurements.

\section{Conclusion}

The study showed a reduction in cardiac sympathetic and parasympathetic modulation in patients with COPD during both $\mathrm{SB}$ and $\mathrm{CB}$. These changes, together with the findings on $\mathrm{TP}$, were the main contributions to the literature. These changes reinforce the need for the analysis of CAM as part of the evaluation of these patients aiming at early detection and treatment of possible cardiac dysautonomia.

\section{Author contributions}

Conception and design of the research: Paschoal MA. Acquisition of data: Gianfrancesco L, Camargo LT, Seixas NB. Analysis and interpretation of the data: Paschoal MA, Gianfrancesco L, Camargo LT, Seixas NB, Paschoal AB. Statistical analysis: Paschoal MA, Gianfrancesco L, Paschoal AB. Writing of the manuscript: Paschoal MA, Gianfrancesco L, Seixas NB. Critical revision of the manuscript for intellectual content: Paschoal MA.

\section{Potential Conflict of Interest}

No potential conflict of interest relevant to this article was reported.

\section{Sources of Funding}

There were no external funding sources for this study.

\section{Study Association}

This study is not associated with any thesis or dissertation work. 


\section{Ethics approval and consent to participate}

This study was approved by the Ethics Committee of the PUC-Campinas under the protocol number 393.938. All the procedures in this study were in accordance with the 1975 Helsinki Declaration, updated in 2013. Informed consent was obtained from all participants included in the study.

\section{References}

1. Vanderlei LC, Pastre CM, Hoshi RA, Carvalho TD, Godoy MF. Noções básicas da variabilidade da frequência cardíaca e sua aplicabilidade clínica. Rev Bras Cir Cardiovasc. 2009; 24(2):205-17.

2. Kawaguchi LY, Nascimento AC, Lima MS, Frigo L, Paula Jr AR, TierraCriollo CJ , et al. Caracterização da variabilidade de frequência cardíaca e sensibilidade do barorreflexo em indivíduos sedentários e atletas do sexo masculino. Rev Bras Med Esporte. 2007,13(4):231-6.

3. Ribeiro JP, Moraes Filho RS. Variabilidade da frequência cardíaca como instrumento de investigação do sistema nervoso autônomo. Rev Bras Hipertens. 2005;12(1):14-20.

4. Akselrod S, Gordon D, Madwed JB, Snidman NC, Shannon DC, Cohen RJ. Hemodynamic regulation: investigation by spectral analysis. Am J Physiol. 1985;249(4 Pt 2):H867-75.

5. Carvalho Td, Pastre CM, Rossi CR, Abreu LC, Valenti VE, Vanderlei LC. Índices geométricos de variabilidade da frequência cardíaca na doença pulmonar obstrutiva crônica. Rev Port Pneumol. 2011;17(6):260-5

6. Sin DD, Wong E, Mayers I, Lien DC, Feeny D, Cheung H, Gan WQ, et al. Effects of nocturnal noninvasive mechanical ventilation on heart rate variability of patients with advanced COPD. Chest. 2007 ;131(1):156-63.

7. Mendes FAR, Moreno IL, Durand MT, Pastre CM, Ramos E, Vanderlei LC. Análise das respostas do sistema cardiovascular ao teste de capacidade vital forçada na DPOC. Rev Bras Fisioter. 2011; 15(2):102-8.

8. Roque AL, Valenti VE, Massetti T, Silva TD, Monteiro CB, Oliveira FR, et al. Chronic obstructive pulmonary disease and heart rate variability: a literature update. Int Arch Med. 2014 Oct;7:43.

9. Pantoni CB, Reis MS, Martins LE, Catai AM, Costa D, Borghi-Silva A. Study on autonomic heart rate modulation at rest among elderly patients with chronic obstructive pulmonary disease. Rev Bras Fisioter. 2007;11(1):35-41.

10. Camillo CA, Pitta F, Possani HV, Barbosa MV, Marques DS, Cavalheri $\mathrm{V}$, et al. Heart rate variability and disease characteristics in patients with COPD. Lung. 2008;186(6):393-401

11. Paschoal MA, Petrelluzzi KF, Gonçalves NV. Estudo da variabilidade da frequência cardíaca em pacientes com doença pulmonar obstrutiva crônica. Rev Ciênc Méd. 2002; 11(1):27-37.

12. Reis MS, Deus AP, Simões RP, Aniceto IA, Catai AM, Borghi-Silva A. Autonomic control of heart rate in patients with chronic cardiorespiratory disease and in healthy participants at rest and during a respiratory sinus arrhythmia maneuver. Rev Bras Fisioter. 2010;14(2)106-13.

13. Chen WL, Chen Gy, Kuoa CD. Hypoxemia and autonomic nervous dysfunction in patients with chronic obstructive pulmonary disease. Respir Med. 2006;100(9):1547-53.

14. Barth J, Del Vecchio FB. Efeitos da frequência ventilatória sobre os índices da variabilidade da frequência cardíaca. Revista Iberoamericana de Arritmología. 2014 5(1):185-93.
15. Acharya UR, Joseph KP, Kannathal N, Lim CM, Suri JS. Heart rate variability: a review. Med Bio Eng Comput. 2006;44(12):1031-51.

16. Smilde TD, van Veldhuisen DJ, van den Berg MP. Prognostic value of heart rate variability and ventricular arrhythmias during 13-year followup in patients with mild to moderate heart failure. Clin Res Cardiol. 2009;98(4):233-9.

17. Andresen D, Bruggemann T, Behrens S, Ehlers C. Heart rate response to provocative maneuvers. In: Malik M, Camm AJ (eds) Heart rate variability. Hoboken (NJ): Wiley-Blackwell; 1995. p.267-74.

18. Task Force of the European Society of Cardiology and the North American Society of Pacing and Electrophysiology. Heart Rate Variability - Standards of measurement, physiological interpretation, and clinical use. Circulation. 1996;93(5):1043-65.

19. Paschoal MA, Volanti VM, Pires CS, Fernandes FC. Variabilidade da frequência cardíaca em diferentes faixas etárias. Rev Bras Fisioter. 2006;10(4):413-9.

20. Pagani M, Lucini D, Pizzinelli P, Sergi M, Bosisio E, Mela GS, et al. Effects of aging and of chronic obstructive pulmonary disease on RR interval variability. J Aut Nerv Syst. 1996;59(3):125-32.

21. Chethan HA, Murthy N, Basavaraju K. Comparative study of heart rate variability in normal and obese young adult males. Int J Biol Med Res. 2012;3(2):1621-3.

22. Sociedade Brasileira de Cardiologia. Sociedade Brasileira de Hipertensão; Sociedade Brasileira de Nefrologia. VI Diretrizes Brasileiras de Hipertensão. Arq Bras Cardiol. 2010;95(1 Suppl 1):1-51.

23. Schettino CD, Deus FC, Gonçalves AA, Wallace E. Relação entre DPOC e doença Cardiovascular. Pulmão (RJ). 2013;22(2):19-23.

24. Dourado VZ, Tanni SE, Vale AS, Faganello MM, Sanchez FF, Godoy I. Manifestações sistêmicas na doença pulmonar obstrutiva crônica. J Bras Pneumol. 2006;32(2):161-71.

25. Volterrani M, Scalvini S, Mazzuero G, Lanfranchi P, Colombo R, Clark $\mathrm{AL}$, et al. Decreased heart rate variability in patients with chronic obstructive pulmonary disease. Chest. 1994;106(5):1432-7.

26. Gunduz H, Talay F, Arinc H, Ozyildirim S, Akdemir R, Yolcu M, et al. Heart rate variability and heart rate turbulence in patients with chronic obstructive pulmonary disease. Cardiol J. 2009;16(6):553-9.

27. Heathers JA. Everything Hertz: methodological issues in short-term frequency-domain HRV. Front Physiol. 2014 May;5:177.

28. Van Gestel AJ, Steier J. Autonomic dysfunction in patients with chronic obstructive pulmonary disease (COPD). J Thorac Dis. 2010;2(4):215-22.

29. Antonelli Incalzi R, Corsonello A, Trojano L, Pedone C, Acanfora D, Spada A, et al. Heart rate vascubility and drawing impairment in hypoxemic COPD. Brain and Cognition. 2009;70(1):163-70. 